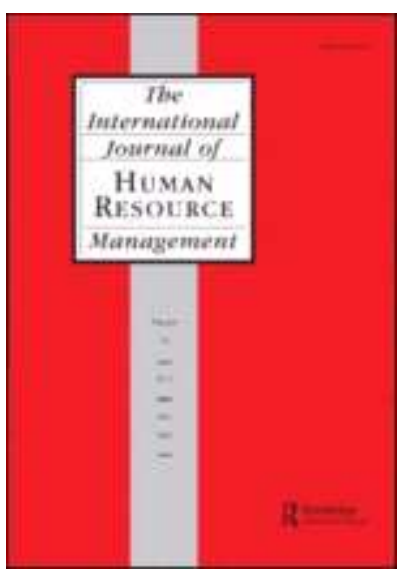

\title{
Chinese hotel employees in the smiling masks: Roles of job satisfaction, burnout, and supervisory support in relationships between emotional labor and performance
}

\begin{tabular}{|r|l|}
\hline Journal: & The International Journal of Human Resource Management \\
\hline Manuscript ID: & RIJH-2010-0264.R1 \\
\hline Manuscript Type: & Original paper \\
\hline Keywords: & $\begin{array}{l}\text { emotional labor, job satisfaction, burnout, supervisory support, } \\
\text { cognitive dissonance }\end{array}$ \\
\hline \multicolumn{2}{|l}{} \\
\hline
\end{tabular}

\section{SCHOLARONE Manuscripts}




\title{
Chinese hotel employees in the smiling masks: Roles of job satisfaction, burnout, and supervisory support in relationships between emotional labor and performance
}

\author{
(Received XX Month Year; final version received XX Month Year)
}

Using survey data from 206 hotel frontline employees (Study 1) and 111 employee-supervisor dyads (Study 2), we examined how the emotional labor of hotel employees was associated with affective and behavioral outcomes. We found that surface acting was negatively related to job satisfaction but positively related to burnout. Meanwhile, deep acting was positively related to job satisfaction but negatively related to burnout. Additionally, job satisfaction and burnout were found to mediate the relationship between emotional labor and work performance. We further found that supervisory support moderated the relationships between emotional labor and job satisfaction and burnout.

Keyword: emotional labor; job satisfaction; burnout; supervisory support; cognitive dissonance

\section{Introduction}

Emotions permeate our lives. They make us aware of people, objects, and events that may affect our thoughts, motivations, goals, and behaviors (Ashford and Humphrey 1995; Diefendorff, Croyle and Gosserand 2005). In workplaces, employees are expected to abide by display rules. These rules are norms requiring employees to display certain emotions during interpersonal transactions that aim to maximize organizational productivity. Van Maanen and Kunda (1989), for example, have suggested that a display of enthusiasm and loyalty by employees is required in corporate culture. Hatfield, Cacipoppo and Rapson (1994) and Pugh (2002) have argued that organizations expect their employees to display cheerful and friendly emotions when interacting with customers, so that these positive emotions will also spread to their customers. This kind of efforts and the control of feelings to express organizationally desired emotions, including facial and bodily displays at work, are referred to as emotional labor (Ashforth and Humphrey 1993; Diefendorff et al. 2005; Gosserand and Diefendorff 2005). Research on emotional labor has shown that displaying positive emotions in service interactions, such as smiling and conveying 
friendliness, is positively associated with the intention of customers to return, with their intention to recommend the service to others, and with the overall perception of service quality (e.g., Pugh 2001). The findings concluded that the more positive emotions are displayed in service interactions, the higher the satisfaction of customers will be. Such positive emotions could be developed and displayed when service providers modified their inner feelings to match the required expressions (deep acting) (e.g., Pugh 2001). Service providers, however, do not always feel positive, and thus they may suppress their felt emotions and fake the desired emotions (surface acting) at work (e.g., Pugh 2001). Hochschild (2003) and Diefendorff and Greguras (2009) have identified these discrepancies as experiences between outward behavior and inner feelings, using samples of smiling attendants and unpleasant debt collectors. Although recent empirical work has shown a positive association between emotional display rules and the use of emotion regulation strategies (i.e., emotional labor) (Brotheridge and Grandey 2002; Grandey 2003; Diefendorff et al. 2005; Bozionelos 2006; Bozionelos and Kiamou 2008), as well as the effect of emotion regulation strategies on performance (Pugh 2001; Diefendorff and Richard 2003), little attention has been paid to identifying the psychological processes involved in the display of these emotions. Thus, we know little about whether or not emotional display affects the affective and behavioral outcomes of employees, and how, if ever, emotional display affects such outcomes. In this research, we use the theory of cognitive dissonance to hypothesize and explain how the use of emotional regulation strategies affect one's psychological states in the form of job satisfaction and burnout, and hence one's work performance. The findings here will not only shed light on the psychological process of emotional labor, but also have implications for the effective control of emotional labor in the workplace. 
1

2

3

4

5

6

7

8

9

This research primarily seeks to examine how emotion regulation strategies (i.e., surface acting and deep acting) affect job satisfaction and burnout, and hence work performance. While hotel frontline staff are required to do much interaction with customers, they are expected to ensure the orderly self conduct (e.g., be warm and polite to customers) throughout the day, every working day. Based on cognitive dissonance theory (Festinger 1954, 1957), we seek to detect any conflicts between required and true emotions following strict regulation of their emotions, and to determine how significant the conflicts might be for job satisfaction and burnout for hotel frontline staff, whose jobs demand a high degree of emotional display. In addition, as customer service providers have to show or exaggerate some emotions and minimize or suppress the expression of unfriendly emotions (Totterdell and Holman 2003), hotel frontline staff may easily feel inconsistencies between their true feelings and displayed emotions, we expect that supervisory support may help to reduce the discrepancies. Thus, this study also seeks to find out whether or not supervisory support reduces the hotel frontline staff's experience of cognitive dissonance. Figure 1 shows the research framework.

[Insert Figure 1 about here]

\section{Theory and hypotheses development}

\section{Emotional labor as a predictor of cognitive dissonance}

Over the past decade, increasing attention has been given to the displays of emotion of employees toward customers during service transactions, and particularly to how organizations seek to direct and control these emotional displays (e.g., Ashforth and Humphrey 1993; Grandey 2003). Displaying organizationally desired emotions to customers has been argued to be a form of labor because it requires the efforts and the self-control of employees to display emotions that 
they may not necessarily privately feel (Bono, Foldes, Vinson and Muros 2007; Bono and Vey 2007). While the current decade has seen the efforts and skills of employees at expressing organizationally desired emotions at work as the key to success for service industries (Pugh 2001; Diefendorff et al. 2005; Gosserand and Diefendorff 2005), little attention has been paid to identifying how employees actually think and react when they display such emotions. How do employees enact such demanding roles? These efforts to engage in emotional labor may cause the dissonance of employees in their cognitions. In the field of social psychology, cognitive dissonance refers to the state of conflict someone experiences when expressing emotions or behavior that are contrary to his or her true feelings or personal beliefs (Festinger 1954, 1957). In reality, it can be asked: to what extent does emotional labor undermine job satisfaction and create burnout?

\section{The effect of emotional labor on job satisfaction and burnout}

Research on emotional labor seeks to describe how employees manage their emotions as part of their work roles (Hochschild 1983; Ashforth and Humphrey 1993; Naring, Briet and Brouwers 2006). Emotional labor entails organizational display rules regardless of one's felt emotions and requires employees to use emotion regulation strategies at work (Gosserand and Diefendorff 2005). Most studies have focused on two emotional labor strategies, namely, surface acting and deep acting, which are commonly used for regulating emotional displays at work. Surface acting involves suppressing felt emotions and faking the desired emotions, while deep acting involves actually experiencing the desired emotions (Grandey 2003; Diefendorff et al. 2005; Gosserand and Diefendorff 2005). 

1

2

3

4

5

6

7

8

9

The aim of using emotional labor strategies is to alter one's emotional displays in order to be consistent with the display rules of one's organization. Grandey (2000) suggested that because surface acting is "acting in bad faith" (i.e., faking the desired emotion) while deep acting is "acting in good faith" (i.e., trying to experience the desired emotion so that a natural display will follow), these emotion regulation strategies may not have uniform effects on affective and behavioral outcomes. Based on the theory of cognitive dissonance (Festinger 1954, 1957) which states that we feel tension (dissonance) when we realize we have to act contrary to our beliefs (cognitions), it is expected that surface acting is negatively related to job satisfaction, whereas deep acting is positively related to it. The argument is that surface acting involves a high level of cognitive dissonance in which employees must make greater efforts to force themselves to display emotions that are quite different from their true feelings. Therefore, these employees may be less likely to have positive moods and emotions at work. Hochschild (2003) drew attention to the loss of recognition between true feelings and required emotional displays. He pointed out that flight attendants used the phrase "go robot" to describe the deadened emotional state they sometimes adopted when their true feelings and required emotional displays were strongly divergent. In contrast, deep acting involves a low level of cognitive dissonance in which employees display emotions that are closer to their true feelings. It appears that this form of emotional labor is more consistent with a strong concern for one's customers (Ashforth and Humphrey 1993). In much the same way as actors attempt to psych themselves up for their work roles, they may develop habitual routines for deep acting, such that emotional labor becomes relatively effortless (Ashforth and Humphrey 1993). Without getting into cognitive dissonance, we suggest that this genuine experience and expression of expected emotions is more likely to 
result in positive moods and thus bring about satisfaction on the job. Therefore, we propose the following hypotheses:

Hypothesis 1a: Surface acting is negatively related to job satisfaction.

Hypothesis $1 b$ : Deep acting is positively related to job satisfaction.

Dissonance theory suggests that if we sense some inconsistency, we feel a high level of tension (Festinger 1954, 1957). Acting as part of one's work role may create a high level of cognitive dissonance. This is because the individual (1) experiences tension from the psychological conflict between his or her required and true emotions, and (2) feels that effortful acting drains his or her resources (Grandey 2003). Studies have shown that emotional dissonance is associated with emotional exhaustion (e.g., Morris and Feldman 1997; Grandey 2003; Bono et al. 2007), while other studies have also found that emotional exhaustion is the core component of burnout (e.g., Maslach and Jackson 1986; Wright and Cropanzano 1998; Halbesleben and Bowler 2007). Surface acting, in which an individual experiences emotional dissonance owing to a discrepancy between outward expressions and inner feelings (Hochschild 2003), is therefore expected to relate to a higher level of burnout. On the other hand, deep acting is a way of decreasing emotional dissonance by modifying internal states to bring feelings into line with expressions (Diefendorff and Richard 2003; Gosserand and Diefendorff 2005). Deep acting increases an individual's understanding of the reasons behind the required emotional displays, assists in acknowledging and experiencing the desired emotions, and helps in minimizing the discrepancy between required emotions and true feelings (cognitive dissonance), as well as preventing emotional exhaustion. To the extent that employees may try to actually feel the emotions that they need to display, their sense of self and their emotional responses will not be adversely 
affected (Bozionelos 2006; Bozionelos and Kiamou 2008). Clearly, employees may naturally feel what they are expected to express without having to work up the emotions. Therefore, we expect that deep acting is related to a lower level of burnout. As such, we posit: Hypothesis 2a: Surface acting is positively related to burnout. Hypothesis 2b: Deep acting is negatively related to burnout.

\section{Supervisory support as a coping resource}

People are not isolated. In times of need, we have parents, relatives, friends, coworkers, and neighbors as part of our social support network. They provide us with the message that we are loved, cared for, and connected to other people in a network of communication and mutual obligation. Because cognitive dissonance can be psychologically aversive (Bono et al. 2007), organizations may try to resolve the dissonance by showing their support to their employees in an exchange for "faking in good faith." Based on the buffering argument, we propose that supervisory support may moderate the effects of emotional labor on job satisfaction and burnout. The principle of the buffering argument is that support provided by one's social network (in this case, supervisors) has a buffering effect on cognitive dissonance because of the ability of the network (supervisors) to protect one (in this case, the employee) from the harmful effects of cognitive dissonance (Karatepe and Aleshinloye 2009). Numerous studies in the literature on stress have clearly documented how the support of a social network can prevent an individual from being overwhelmed by feelings of helplessness and loss of self-esteem (Karatepe and Aleshinloye 2009).

Specifically, we argue that, with a higher level of supervisory support, the negative effects of surface acting on job satisfaction and the negative effects of deep acting on burnout tend to be attenuated, while the positive effects of surface acting on burnout and the positive 
effects of deep acting on job satisfaction tend to be strengthened. The reason for this is that when receiving a high level of support and encouragement from supervisors, subordinates may be more willing to internalize organizationally desired emotions by persisting in displaying these emotions over time and by not easily giving up the display under difficult conditions. However, with a lower level of supervisory support, subordinates would not have the intention to experience the desired emotions and may simply choose to display them without internalizing them. Many prior studies have also pointed out the power of support in moderating the vulnerability to stress. Pazy (2009), for example, have suggested that when people can approach other individuals, they are better able to handle job stress. Based on this line of reasoning, we hypothesize that supervisory support specifically moderates the relationships of surface acting and deep acting to job satisfaction and burnout as follows:

Hypothesis 3a: The negative relationship between surface acting and job satisfaction is weaker when employees have a higher level of supervisory support than when they have a lower level of supervisory support.

Hypothesis 3b: The positive relationship between deep acting and job satisfaction is stronger when employees have a higher level of supervisory support than when they have a lower level of supervisory support.

Hypothesis 4a: The positive relationship between surface acting and burnout is weaker when employees have a higher level of supervisory support than when they have a lower level of supervisory support.

Hypothesis 4b: The negative relationship between deep acting and burnout is weaker when employees have a higher level of supervisory support than when they have a lower level of supervisory support. 


\section{Job satisfaction and burnout as mediators}

When engaging in surface acting, employees modify their displays without shaping their inner feelings. Employees tend to conform to the display rules to keep their jobs but not out of a true concern for the customers and the organization. Thus, surface acting represents a fake display and could reduce the authenticity of service quality. Research supports a negative link between surface acting and service performance (e.g., Ashforth and Humphrey 1993; Grandey 2003). If employees typically engage in surface acting by simply suppressing negative moods, then their superficial expressions may be very fragile (Grandey 2003). Therefore, we include a direct link based on previous findings (e.g., Grandey 2003). Mediated paths through job satisfaction and burnout are proposed: surface acting has an effect on service performance because it diminishes the level of positive attitude to a job but increases the level of emotional exhaustion.

Hypothesis 5a: Job satisfaction mediates the negative relationship between surface acting and service performance.

Hypothesis 5b: Burnout mediates the negative relationship between surface acting and service performance.

Similarly, deep acting may directly affect the ratings of service performance. In deep acting, employees attempt to modify or internalize feelings to match the required emotions. This good intention normally leads to the provision of a higher quality of service because employees try to feel empathy for their customers' concerns and think about the benefit to the organization (Grandey 2000). Consistent with Ashforth and Humphrey's (1993) proposition, research has supported a direct, positive relationship between deep acting and service performance in a sample of working adults from a variety of occupations, including services and sales, 
professional, technical, management, clerical, education, and health care (Gosserand and Diefendorff 2005). Therefore, the effect of deep acting on service outcomes may be mediated by a satisfactory attitude toward a job and burnout on the job.

Hypothesis 6a: Job satisfaction mediates the positive relationship between deep acting and service performance.

Hypothesis 6b: Burnout mediates the positive relationship between deep acting and service performance.

Two studies were conducted to examine the above hypotheses. To test our initial idea of the moderating effect of supervisory support on the relationship between emotional labor and job satisfaction, we conducted Study 1. Subsequently, we conducted Study 2 to further confirm the initial idea and extend the model to include the mediating effects of job satisfaction and burnout on the relationship between emotional labor and work performance. In summary, we only tested Hypotheses 1a, 1b, 3a, and 3b in Study 1. We then conducted Study 2 to examine all of the hypotheses.

\section{$\underline{\text { Research Context }}$}

We conducted two studies to examine our research model (see Figure 1). In Study 1, we tested the main effects of surface acting and deep acting (Hypotheses 1a and 1b), and their interactive effects with supervisory support (Hypotheses 3a and 3b) on job satisfaction. In Study 2, we aimed to replicate the findings of Study 1, and also to test the main effects of surface acting and deep acting (Hypotheses $2 \mathrm{a}$ and $2 \mathrm{~b}$ ), and their interactive effects with supervisory support (Hypotheses 4a and 4b) on burnout, the mediating effects of job satisfaction on the 


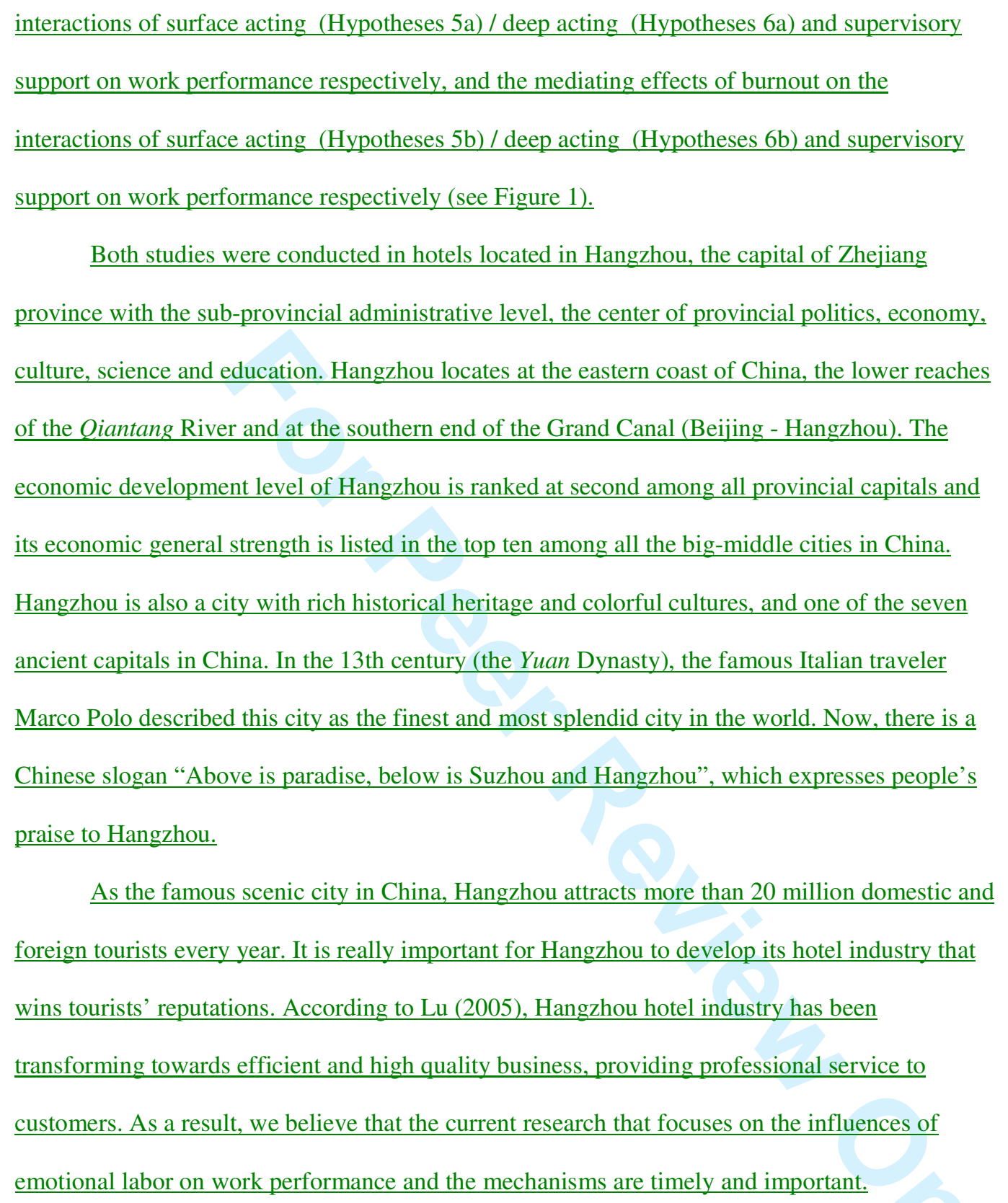




\title{
Study one: Method \\ Participants and procedure
}

The participants were 206 frontline staff working in three branches of a hotel located in Hangzhou in mainland China. The data were collected in November 2006. Three of the authors

Deleted: wo met with all the respondents in person (in groups), to brief them about the purposes of the study and to explain the procedures of the survey. The respondents received a covering letter explaining the study, a questionnaire, and a return envelope. To ensure confidentiality, the respondents were instructed to seal the completed questionnaires in the envelopes and return them directly to the researchers on site. Out of 261 questionnaires, 206 usable questionnaires were returned, giving a usable response rate of 78.9 percent. The mean age of respondents was 25.25 years old (ranging from 16 to 54 years old). The respondents had worked for their companies for an average of 5.21 years (ranging from .08 to 28.5 years) and had, on average, a senior secondary level of education.

\begin{abstract}
Measures
Surface Acting and Deep Acting We assessed the surface acting and deep acting of the respondents using seven-item and four-item measures ( 1 = strongly disagree; 7 = strongly agree), respectively, as developed by Diefendorff et al. (2005). A sample item for surface acting was "I fake the emotions I show when dealing with customers," and a sample item for deep acting was "I try to actually experience the emotions that I must show to customers." We conducted a confirmatory factor analysis (CFA) using AMOS 17 to assess the validity of this measure. The results indicated that the two-factor model $\left(\chi^{2}=125.39, d f=43, C F I=.93, T L I=.91, R M S E A\right.$ $=.08)$ yielded a better fit than the single-factor model $\left(\chi^{2}=262.21, d f=44, C F I=.74, T L I=.67\right.$, $R M S E A=.16)$. The $\chi^{2}$ change was $136.82(\Delta d f=1, p<.001)$. This meant that the respondents
\end{abstract}


could differentiate the items for the two constructs. The alpha coefficients were .88 and .82 , respectively, for surface acting and deep acting.

Supervisory Support A four-item scale developed by Hughes (2001) and validated by Kickul and Posig (2001) was used to ask the respondents the perceived extent of the supportiveness of their immediate supervisors. A sample item was "My supervisor cares about my emotional well-being" ( 1 = strongly disagree; 7 = strongly agree). The alpha coefficient was .91 .

Job Satisfaction We measured the job satisfaction of the respondents using a three-item scale developed by Cammann, Fichman, Jenkins, and Klesh (1983). A sample item was "I am satisfied with my current job" ( 1 = strongly disagree; 7 = strongly agree $)$. The alpha coefficient was .84 .

Control variables Because age, education level, and tenure of current job appear to be related to job satisfaction (Blau 1999; Epitropaki and Martin 2005; Frow 2007) and emotion regulation strategies (Kruml and Geddes 2000), we controlled for these variables in the regression analyses. Age and position tenure were self-reported in number of years. Educational level was coded as: junior secondary or lower $=1$; senior secondary $=2$; vocational college $=3$; and university or higher $=4$.

\section{Translation of questionnaire items}

The questionnaire items were originally written in English and then translated into Chinese by a bilingual scholar of Mandarin and English. A back-translation method (Brislin, Lonner and Thorndike 1973) was used, with the items being translated back into English by another bilingual 
scholar of Mandarin and English to ensure that the versions of the items in both languages had a high degree of similarity in meaning.

\section{Study one: Results \\ Preliminary analyses}

Confirmatory Factor Analyses

In order to statistically discriminate the four key variables (surface acting, deep acting, supervisory emotional support, and job satisfaction), we conducted a CFA. The results showed that the four-factor model $\left(\chi^{2}=256.47, d f=129, C F I=.91, T L I=.90, R M S E A=.07\right)$ yielded a better fit than the single-factor model $\left(\chi^{2}=936.79, d f=135, C F I=.44, T L I=.37, R M S E A=.17\right)$. The $\chi^{2}$ change was $680.31(\Delta d f=6, p<.001)$.

\section{Descriptive Statistics}

The means, standard deviations, and zero-order Pearson correlations of all the key variables are presented in Table 1.

\section{[Insert Table 1 about here]}

\section{Tests of hypotheses}

We conducted a hierarchical multiple regression using SPSS 17 to test Hypotheses 1a, 1b, 3a, and 3b, following the steps suggested by Muller, Judd, and Yzerbyt (2005). As shown in Table 2, after regressing job satisfaction on the control variables in Step 1, we entered surface acting and deep acting in Step 2. Surface acting was found to be negatively related to job satisfaction $(\beta=$ $\left..13, p<.05 ; \Delta R^{2}=.09, p<.001\right)$ while deep acting was found to be positively related to job satisfaction $\left(\beta=.25, p<.001 ; \Delta R^{2}=.09, p<.001\right)$. The results supported Hypotheses $1 \mathrm{a}$ and $1 \mathrm{~b}$, 
which predicted that surface acting and deep acting are negatively and positively related to job satisfaction, respectively. In Steps 3 and 4, we respectively entered supervisory emotional support and interactions. Table 2 shows that supervisory emotional support positively moderated the effect of surface acting on job satisfaction $\left(\beta=.16, p<.01 ; \Delta R^{2}=.06, p<.001\right)$ and the effect of deep acting on job satisfaction $\left(\beta=.19, p<.01 ; \Delta R^{2}=.06, p<.001\right)$.

[Insert Table 2 about here]

To determine whether or not the forms of the interactions matched those suggested by Hypotheses $3 \mathrm{a}$ and $3 \mathrm{~b}$, we tested the simple slopes of high supervisory support (one standard deviation above the mean) and low supervisory support (one standard deviation below the mean). In support of Hypothesis 3a, we found that surface acting was more negatively related to job satisfaction when the employees had a lower level of supervisory support (simple slope test: $\beta=$ $.33, p<.001$ ) than when the employees had a higher level of supervisory support (simple slope test: $\beta=-.07$, n.s.). Furthermore, in support of Hypothesis $3 \mathrm{~b}$, we found that deep acting was more positively related to job satisfaction when the employees had a higher level of supervisory support (simple slope test: $\beta=.37, p<.001$ ) than when they had a lower level of supervisory support (simple slope test: $\beta=.07$, n.s.).

[Insert Figure 2 about here]

\section{Study two: Method}

\section{Participants and procedure}

The sample for the questionnaire surveys included 111 frontline staff and their immediate supervisors working in three hotels (different from the hotels sampled in Study 1) located in 
Hangzhou in mainland China. The data were collected in January 2008. Two sets of

questionnaires were used in the study: one for the frontline staff and another for their immediate supervisors. Questionnaires were administered to the frontline staff and their immediate

supervisors separately. Four of the authors visited all the respondents in person (with the

supervisors and subordinates grouped separately) and conducted the survey following the same

procedure used in Study 1. Out of 148 questionnaire-sets (for 148 subordinate-supervisor dyads),

111 usable questionnaire-sets were returned. The usable response rate was 75.0 percent for both

supervisors and subordinates. These 111 subordinates were supervised by 20 immediate

supervisors. The maximum number of surveys completed by a single supervisor was 11 . For the subordinate sample, the mean age was 24.33 years old (ranging from 16 to 43 years old), the mean tenure was 4.28 years (ranging from .04 to 20 years), and the average educational level was close to senior secondary. For the supervisor sample, the mean age and organizational tenure were 31.19 years old (ranging from 20 to 45 years old) and 9.86 years (ranging from 2.4 to 27 years), respectively, and their mean education was senior secondary. The average length of the supervisor-subordinate relationship was 1.54 years (ranging from .04 to 14 years).

\footnotetext{
Measures

Apart from burnout (the mediator), work performance (the dependent variable), and the control variables, the key measures, namely, surface acting and deep acting (the independent variables), supervisory support (the moderator), and job satisfaction (the mediator), were the same as in Study 1. Surface acting, deep acting, supervisory support, burnout, and job satisfaction were rated by the employees, while work performance was rated by their immediate supervisors.
} 

1

2

3

4

5

6

7

8

9

Burnout The burnout of the frontline staff was assessed using the 21-item scale developed by Salmela-Aro (2009). A sample item was "I am tired" ( 1 = never; $7=$ always). The Cronbach's alpha was .95 .

Work Performance A three-item 7-point scale performance rating developed by Van Scotter and Motowidlo (1996) was used to measure how the supervisors perceived the overall work performance of their subordinates $(1=$ very unsatisfactory; $7=$ excellent $)$. A sample item addressed whether or not the subordinate exceeded, met, or did not meet the expected work performance. The Cronbach's alpha coefficients were .95 .

Control Variables Because the data were obtained from both supervisors and subordinates, the potential effects of various demographic variables were controlled in the analyses. The control variables included education level, age, organizational tenure, supervisor's gender, and the length of the supervisor-subordinate relationship.

\section{Study two: Results}

\section{Preliminary analyses}

\section{Confirmatory Factor Analyses}

We conducted a CFA to further evaluate the discriminant validity of surface acting and deep acting. The results suggested that the hypothesized two-factor model $(C F I=.96, T L I=.95$, $R M S E A=.05)$ yielded a better fit than the single-factor model $(C F I=.79, T L I=.72, R M S E A$ $=.11)$, with a $\chi^{2}$ change of $46.04(\Delta d f=1, p<.001)$. In order to statistically discriminate the five key variables (surface acting, deep acting, supervisory emotional support, job satisfaction, and burnout) as rated by the subordinates, we conducted a CFA. The results showed that the five- 
factor model $(C F I=.90, T L I=.90, R M S E A=.06)$ yielded a better fit than the single-factor

model $(C F I=.66, T L I=.63, R M S E A=.10)$. The $\chi^{2}$ change was $519.82(\Delta d f=10, p<.001)$.

\section{Descriptive Statistics}

The means, standard deviations, and zero-order Pearson correlations of all the key variables are presented in Table 3.

[Insert Table 3 about here]

\section{Tests of hypotheses}

Following the steps suggested by Muller et al. (2005), a hierarchical regression analysis was conducted to test the hypotheses (Hypotheses 1a, 1b, 2a, 2b, 3a, 3b, 4a, and 4b) and mediating models (Hypotheses 5a, 5b, 6a, and 6b). As shown in Table 4 (Model 2), surface acting ( $\beta=-.18$, $\left.p<.05 ; \Delta R^{2}=.08, p<.01\right)$ and deep acting $\left(\beta=.19, p<.05 ; \Delta R^{2}=.08, p<.01\right)$ were negatively and positively related to work performance, respectively. The results fulfilled the first requirement of mediation.

[Insert Table 4 about here]

Second, surface acting was found to be negatively related to job satisfaction $(\beta=-19, p$ $\left.<.05 ; \Delta R^{2}=.08, p<.01\right)$ while deep acting was found to be positively related to job satisfaction $\left(\beta=.21, p<.05 ; \Delta R^{2}=.08, p<.01\right)($ Table 4 , Model 6$)$, thus meeting the second requirement of mediation (job satisfaction as a mediator) and lending support to Hypotheses 1a and 1b. 
Next, we found that surface acting was positively related to burnout $(\beta=.20, p<.05$; $\left.\Delta R^{2}=.08, p<.01\right)$ while deep acting was negatively related $\left(\beta=-.19, p<.05 ; \Delta R^{2}=.08, p<.01\right)$ (Table 4, Model 10). Hence, the results met the second requirement of mediation (burnout as a mediator) and supported Hypotheses $2 \mathrm{a}$ and $2 \mathrm{~b}$.

Furthermore, Models 3 and 4 of Table 4 reveal that job satisfaction $(\beta=.22, p<.05$; $\left.\Delta R^{2}=.02, p<.05\right)$ and burnout $\left(\beta=-.25, p<.05 ; \Delta R^{2}=.02, p<.05\right)$ were positively and negatively related to work performance, respectively, thus meeting the third requirement for the two mediation models. In contrast, the effects of surface acting and deep acting on work performance were found to be no longer significant. These results suggested that job satisfaction and burnout completely mediated the effects of surface acting and deep acting on work performance. Therefore, Hypotheses 5a, 5b, 6a, and $6 \mathrm{~b}$ were all supported.

In addition, the interaction of surface acting and support $\left(\beta=.25, p<.01 ; \Delta R^{2}=.05, p\right.$ $<.01)$ and the interaction of deep acting and support $\left(\beta=.20, p<.01 ; \Delta R^{2}=.05, p<.01\right)$ on job satisfaction were significant (Table 4, Model 8). The interactive effects are plotted in Figure 3. In support of Hypothesis 3a, simple slope analyses showed that surface acting was more negatively related to job satisfaction when the employees had a lower level of support (simple slope test: $\beta$ $=-.23, p<.01$ ) than when the employees had a higher level of support (simple slope test: $\beta=.09$, n.s.) from their supervisors. Furthermore, in support of Hypothesis 3b, we found that deep acting was more positively related to job satisfaction when the employees had a higher level of support (simple slope test: $\beta=.27, p<.01$ ) than when they had a lower level of support (simple slope test: $\beta=.02, n . s$.$) . Therefore, Hypotheses 3 \mathrm{a}$ and $3 \mathrm{~b}$ were supported.

[Insert Figure 3 about here] 
Next, we found that the interaction of surface acting and support $(\beta=-.37, p<.001$; $\left.\Delta R^{2}=.12, p<.001\right)$ and the interaction of deep acting and support $\left(\beta=-.30, p<.01 ; \Delta R^{2}=.12, p\right.$ $<.001$ ) on burnout were significant (Table 4, Model 12). The plots in Figure 4 show that surface acting was more significantly related to burnout when the employees had a lower level of support (simple slope test: $\beta=.41, p<.001$ ) than when they had a higher level of support (simple slope test: $\beta=.00$, n.s.). The figure also shows that deep acting was more negatively related to burnout when the employees had a lower level of support $(\beta=-.20, p<.05)$ than when they had a higher level of support (simple slope test: $\beta=.02$, n.s.) from their supervisors. Therefore, Hypotheses $4 \mathrm{a}$ and $4 \mathrm{~b}$ were also supported. In summary, all of the hypotheses were supported.

\title{
[Insert Figure 4 about here]
}

\author{
Discussion \\ Interest in emotional labor continues to grow as we seek to describe how individuals manage \\ their emotions as part of their work roles. Most research on emotional labor reveals that the more \\ committed the individuals are in abiding by the emotional display rules, the stronger the \\ relationships of those display rules are with the use of emotion regulation strategies including \\ surface acting and deep acting (e.g., Gosserand and Diefendorff 2005). Understanding how \\ individuals actually feel and react when they display such emotions at work is particularly
}



1

2

3

4

5

6

7

8

9

important, and yet has rarely been studied. Addressing this gap is the focus and contribution of this research.

We found that surface acting and deep acting are negatively and positively related to job satisfaction respectively, while both are positively and negatively related to burnout respectively. Additionally, we found that job satisfaction and burnout mediate the effect of surface acting and deep acting on work performance. Past research has often undermined the inner psychological processes of employees in displaying emotions (e.g., Diefendorff and Richard 2003; Glomb, Kammeyer-Mueller and Rotundo 2004). This research contributes to the literature on emotional labor by considering the role of cognitive dissonance in explaining the psychological processes induced when displaying emotions at work. The results of the present study suggest that there is an experience of cognitive dissonance influencing whether employees are satisfied with their jobs or suffer from emotional exhaustion when they display the required emotions. Hence, this experience of cognitive dissonance affects work performance.

It might be that employees try to cope with job dissatisfaction and cognitive exhaustion by revealing their negative feelings to customers in order to reduce the cognitive dissonance they experience. Therefore, mere emotional labor does not necessarily result in higher performance; individuals must minimize the level of cognitive dissonance or inconsistency between the required display of emotion and their true feelings. Organizations should strive to ensure that their employees modify their inner feelings so that the latter are closer to the required emotions. One way of helping employees to modify their inner feelings so that they are closer to the required emotions is to raise the value of "acting in good faith" (e.g., promoting a linkage between effective emotional display and organizational rewards). As Glomb, Kammeyer-Mueller, and Rotundo (2004) suggested, higher levels of demand for emotional labor are associated with 
lower wage rates for jobs low in cognitive demands, and with higher wage rates for jobs high in cognitive demands. Higher wages are treated as compensation for higher cognitive demands.

Another way to help employees to modify their inner feelings may be to increase their feeling that they are being cared for and supported by their supervisors and the organizations they work for (e.g., that supervisors empathize with employees when the latter experience difficulties at work, that they understand their needs, and that they establish personal and career goals with them). We found that, consistent with these suggestions, supervisory support strengthens the positive effects of deep acting and attenuates the negative effects of surface acting on job satisfaction and burnout. According to the self-perception theory, individuals infer from their own behavior when they are in a situation that causes them to suffer from a high level of cognitive dissonance (Fazio 1987). An individual will repeatedly develop a negative or destructive attitude toward a behavior, which can give rise to a conflict between his or her inner feelings and behavior. Therefore, supervisory support may be a coping resource. Much research points to the power of support in coping with stress both at work and in life (Pazy and Ganzach 2009). Working at developing, maintaining, and expanding one's supportive relationship with one's supervisor allows one to share feelings, joys, and worries, so that one is more likely to think positively and experience a positive psychological state.

Finally, as shown in our findings, surface acting has a direct negative relationship with work performance, while deep acting has a direct positive relationship with work performance. We suggest that when organizations are attempting to reduce the amount of surface acting, an appropriate selection is needed. The findings of Diefendorff et al. (2005) suggested that individuals high in extraversion tend to fake the desired emotions less than individuals low in extraversion. Because these individuals experience positive emotions more often, they may have 

1

2

3

4

5

6

7

8

9

less of a need to surface act, and be more likely to display their true feelings at work. In addition, the authors found a negative relationship between conscientiousness and surface acting. They argued that conscientiousness reflects the extent to which a person is careful, thorough, and responsible. Individuals high in conscientiousness tend to follow emotional display rules by working to be as genuine as possible in their expressions (Diefendorff et al. 2005). Furthermore, the findings on agreeableness suggested that individuals who value positive interactions with others are less likely to engage in surface acting. Researchers (Diefendorff et al. 2005) supported this argument by explaining that agreeable individuals were more equipped to display genuine positive emotions (i.e., deep acting) as they emphasized the maintenance of positive relationships with others and were thus more likely to avoid being perceived as insincere. These findings provided indicators for practitioners in the service industry to help them select employees who were high in extraversion, conscientiousness, and agreeableness.

\section{Limitations and future research directions}

This research has four main limitations. First, the shared method variance in the self-reported variables imposes a need for caution in the interpretation of the findings. Although we focused on the relationships between the frontline employee's own choices of display strategies (i.e., surface acting and deep acting) and their inner feelings or psychological states (i.e., job satisfaction and burnout), future studies should look broadly at supervisor ratings, or customer perceptions of the emotional displays of employees, or both. Second, the supervisors but not customers were asked to assess the work performance of the frontline staff. Therefore, the supervisors' ratings of the service performance may lead to an under- or overestimation our predictions because they are not directly the people who interact with the service providers (Luo 
and Homburg 2007). As Grandey (2003) argued, observers (e.g., supervisors) may positively perceive the genuine nature of deep acting and negatively perceive as insincere the faked nature of surface acting. It would be interesting, then, to investigate these relationships using different sources of performance rating such as customers' perceptions of the work performance of employees and customer satisfaction. Third, this study used a cross-sectional design. As such, we cannot infer the causality among the variables. One may argue that surface acting may not always be considered all that bad; indeed, it may be better than displaying true emotions when an individual is in a bad mood. Future research could use a longitudinal research design in order to test for the possibility of an arguable relationship in which deep acting may lead to high levels of emotional exhaustion, and that could be why an employee would use surface acting as a lowerinvestment way of meeting the required display rules (Grandey 2003). Fourth, the sample used was homogeneous in terms of gender (all subordinates were female) and job type (frontline service), and both of the studies were conducted in a single city (i.e., Hangzhou) only, such that the question of generalizability might be raised. Therefore, when interpreting the findings of this research, we need to think of these boundary conditions. Future research might examine whether or not the findings of the present study would occur in a sample from a variety of occupations and regions, the results of which may be informative to researchers interested in current dynamic work contexts.

Nonetheless, this study provides new insights into how the psychological processes of employees may play a vital role in the relationship of emotional regulation strategies to affective and behavioral outcomes based on the theory of cognitive dissonance. It also provides evidence for the importance of encouraging and training employees in deep acting, which is better than 
surface acting in the delivery of services. In addition, it suggests that supervisors should provide support to their employees.

1

2

3

4

5

6

7

8

9

10

11

12

13

14

15

16

17

18

19

20

21

22

23

24

25

26

27

28

29

30

31

32

33

34

35

36

37

38

39

40

41

42

43

44

45

46

47

48

49

50

51

52

53

54

55

56

57

58

59

60 


\section{References}

Ashford, B.E., and Humphrey, R.H. (1995), 'Emotion in the Workplace: A Reappraisal,' Human Relations, $48,97-125$.

Ashforth, B.E., and Humphrey, R.H. (1993), 'Emotional Labor in Service Roles: The Influence of Identity,' Academy of Management Review, 18, 88-115.

Blau, G. (1999), 'Early-Career Job Factors Influencing the Professional Commitment of Medical Technologists,' Academy of Management Journal, 42, 687-695.

Bono, J.E., Foldes, H.J., Vinson, G., and Muros, J.P. (2007), 'Workplace Emotions: The Role of Supervision and Leadership,' Journal of Applied Psychology, 92, 1357-1367.

Bono, J.E., and Vey, M.A. (2007), 'Personality and Emotional Performance: Extraversion, Neuroticism, and Self-Monitoring,' Journal of Occupational Health Psychology, 12, 177-192. Bozionelos, N. (2006), 'Mentoring and Expressive Network Resources: Their Relationship with Career Success and Emotional Exhaustion among Hellenes Employees Involved in Emotion Work,' International Journal of Human Resource Management, 17, 362-378. Bozionelos, N., and Kiamou, K. (2008), 'Emotion Work in the Hellenic Frontline Services Environment: How It Relates to Emotional Exhaustion and Work Attitudes,' International Journal of Human Resource Management, 19, 1108-1130.

Brislin, R., Lonner, W.J., and Thorndike, R. (1973), Cross-Cultural Research Methods, New York: Wiley.

Brotheridge, C.M., and Grandey, A.A. (2002), 'Emotional Labor and Burnout: Comparing Two Perspectives Of "People Work",' Journal of Vocational Behavior, 60, 17-39.

Cammann, C., Fichman, M., Jenkins, G.D., and Klesh, J.R. (1983), 'Assessing the Attitudes and Perceptions of Organizational Members', in Assessing Organizational Change, eds. S.E.

Seashore, E.E. Lawler III, P.H. Mirvis and C. Cammann, John Wiley and Sons, Inc., pp. 71-138. Diefendorff, J.M., Croyle, M.H., and Gosserand, R.H. (2005), 'The Dimensionality and Antecedents of Emotional Labor Strategies,' Journal of Vocational Behavior, 66, 339-357. Diefendorff, J.M., and Greguras, G.J. (2009), 'Contextualizing Emotional Display Rules: Examining the Roles of Targets and Discrete Emotions in Shaping Display Rule Perceptions,' Journal of Management, 35, 880-898.

Diefendorff, J.M., and Richard, E.M. (2003), 'Antecedents and Consequences of Emotional Display Rule Perceptions,' Journal of Applied Psychology, 88, 284-294.

Epitropaki, O., and Martin, R. (2005), 'From Ideal to Real: A Longitudinal Study of the Role of Implicit Leadership Theories on Leader-Member Exchanges and Employee Outcomes,' Journal of Applied Psychology, 90, 659-676.

Fazio, R.H. (1987), 'Self-Perception Theory: A Current Perspective', in Social Influence: The Ontario Symposium, eds. M.P. Zanna, J.M. Olson and C.P. Herman, Hillsdale, NJ: Erlbaum, pp. 129-150.

Festinger, L. (1954), 'A Theory of Social Comparison Processes,' Human Relations, 7, 117-140. Festinger, L. (1957), A Theory of Cognitive Dissonance, Palo Alto, CA: Stanford University Press.

Frow, P. (2007), 'The Meaning of Commitment in Professional Service Relationships: A Study of the Meaning of Commitment Used by Lawyers and Their Clients,' Journal of Marketing Management, 23, 243 - 265.

Glomb, T.M., Kammeyer-Mueller, J.D., and Rotundo, M. (2004), 'Emotional Labor Demands and Compensating Wage Differentials,' Journal of Applied Psychology, 89, 700-714. 
Gosserand, R.H., and Diefendorff, J.M. (2005), 'Emotional Display Rules and Emotional Labor: The Moderating Role of Commitment,' Journal of Applied Psychology, 90, 1256-1264. Grandey, A.A. (2000), 'Emotion Regulation in the Workplace: A New Way to Conceptualize Emotional Labor,' Journal of Occupational Health Psychology, 5, 95-110. Grandey, A.A. (2003), 'When "The Show Must Go On": Surface Acting and Deep Acting as Determinants of Emotional Exhaustion and Peer-Rated Service Delivery,' Academy of Management Journal, 46, 86-96.

Halbesleben, J.R.B., and Bowler, W.M. (2007), 'Emotional Exhaustion and Job Performance: The Mediating Role of Motivation,' Journal of Applied Psychology, 92, 93-106. Hatfield, E., Cacioppo, J.T., and Rapson, R.L. (1994), Emotional Contagion, Cambridge, England: Cambridge University Press.

Hochschild, A.R. (1983), The Managed Heart: Commercialization of Human Feeling, CA: University of California Press.

Hochschild, A.R. (2003), The Managed Heart : Commercialization of Human Feeling, Hughes, R.E. (2001), 'Deciding to Leave but Staying: Teacher Burnout, Precursors and Turnover,' International Journal of Human Resource Management, 12, 288-298.

Karatepe, O.M., and Aleshinloye, K.D. (2009), 'Emotional Dissonance and Emotional Exhaustion among Hotel Employees in Nigeria,' International Journal of Hospitality Management, 28, 349-358.

Kickul, J., and Posig, M. (2001), 'Supervisory Emotional Support and Burnout: An Explanation of Reverse Buffering Effects,' Journal of Managerial Issues, 13, 328-344.

Kruml, S.M., and Geddes, D. (2000), 'Exploring the Dimensions of Emotional Labor: The Heart of Hochschild's Work,' Management Communication Quarterly, 14, 8-49.

Lu, Y. (2005, December 28), Hangzhou Hotel Industry Improves Quality to Salute Leisure Expo. Message posted to http://en.gotohz.com/web/guest/histroy.

Luo, X.M., and Homburg, C. (2007), 'Neglected Outcomes of Customer Satisfaction,' Journal of Marketing, 71, 133-149.

Maslach, C., and Jackson, S.E. (1986), Maslach Burnout Inventory Manual, Palo Alto, CA: Consulting Psychologists Press.

Morris, J., and Feldman, D.C. (1997), 'Managing Emotions in the Workplace,' Journal of Managerial Issues, 9, 257-274.

Muller, D., Judd, C.M., and Yzerbyt, V.Y. (2005), 'When Moderation Is Mediated and Mediation Is Moderated,' Journal of Personality and Social Psychology, 89, 852-863.

Naring, G., Briet, M., and Brouwers, A. (2006), 'Beyond Demand-Control: Emotional Labour and Symptoms of Burnout in Teachers,' Work and Stress, 20, 303-315.

Pazy, A., and Ganzach, Y. (2009), 'Pay Contingency and the Effects of Perceived Organizational and Supervisor Support on Performance and Commitment,' Journal of Management, 35, 10071025.

Pugh, S.D. (2001), 'Service with a Smile: Emotional Contagion in the Service Encounter,' Academy of Management Journal, 44, 1018-1027.

Pugh, S.D. (2002), 'Emotional Regulation in Individuals and Dyads: Causes, Costs, and Consequences', in Emotions in the Workplace, eds. R.G. Lord, R. Klimoski and R. Kanfer, San Francisco: Jossey-Bass, pp. 147-182.

Salmela-Aro, K., Tolvanen, A., and Nurmi, J.E. (2009), 'Achievement Strategies During University Studies Predict Early Career Burnout and Engagement,' Journal of Vocational Behavior, 75, 162-172. 
Totterdell, P., and Holman, D. (2003), 'Emotion Regulation in Customer Service Roles: Testing a Model of Emotional Labor,' Journal of Occupational Health Psychology, 8, 55-73.

Van Maanen, J., and Kunda, G. (1989), 'Real Feelings: Emotional Expression and Organizational Cultural', in Research in Organizational Behavior, eds. L.L. Cummings and B.M. Staw, Greenwich, CT: JAI Press, pp. 43-103.

Van Scotter, J.R., and Motowidlo, S.J. (1996), 'Interpersonal Facilitation and Job Dedication as Separate Facets of Contextual Performance,' Journal of Applied Psychology, 81, 525-531.

Wright, T.A., and Cropanzano, R. (1998), 'Emotional Exhaustion as a Predictor of Job Performance and Voluntary Turnover,' Journal of Applied Psychology, 83, 486-493. 
1

2

3

4

5

6

7

8

9

10

11

12

13

14

15

16

17

18

19

20

21

22

23

24

25

26

27

28

29

30

31

32

33

34

35

36

37

38

39

40

41

42

43

44

45

46

47

48

49

50

51

52

53

54

55

56

57

58

59

60

Table 1. Study one: Means, standard deviations, correlations, and reliabilities of measures (in parentheses).

\begin{tabular}{|c|c|c|c|c|c|c|c|c|c|c|c|c|}
\hline & Variables & Mean & SD & 1 & 2 & 3 & 4 & 5 & 6 & 7 & 8 & 9 \\
\hline 1 & Branch dummy 1 & .26 & .44 & --- & & & & & & & & \\
\hline 2 & Branch dummy 2 & .32 & .47 & $-.41^{* * * *}$ & --- & & & & & & & \\
\hline 3 & Age & 25.25 & 7.92 & $-.27^{* * * *}$ & $-.34^{* * * *}$ & --- & & & & & & \\
\hline 4 & Education level & 2.08 & .86 & $-.26^{* * * *}$ & $-.25^{* * *}$ & $.42^{* * * *}$ & --- & & & & & \\
\hline 5 & Tenure (in year) & 5.21 & 7.78 & $-.33^{* * * *}$ & $-.33^{* * *}$ & $.91^{* * * *}$ & $.30^{* * * *}$ & --- & & & & \\
\hline 6 & Surface acting & 4.22 & 1.33 & -.12 & .02 & -.01 & .05 & .00 & $(.88)$ & & & \\
\hline 7 & Deep acting & 5.05 & 1.04 & -.01 & -.10 & .00 & .04 & -.03 & $-.16^{*}$ & $(.82)$ & & \\
\hline 8 & Supervisory support & 5.01 & 1.21 & -.09 & -.06 & .02 & .10 & .00 & .10 & $.22^{* * * *}$ & $(.91)$ & \\
\hline 9 & Job satisfaction & 4.90 & 1.32 & .07 & .12 & $-.16^{*}$ & -.01 & $-.17^{*}$ & $-.18^{* *}$ & $.25^{* * *}$ & $.22^{* * * *}$ & $(.82)$ \\
\hline
\end{tabular}


Table 2. Study one: Hierarchical regression results for the moderating model.

\begin{tabular}{lcccc}
\hline & \multicolumn{5}{c}{ Job satisfaction } \\
\cline { 2 - 5 } Variable & Model 1 & Model 2 & Model 3 & Model 4 \\
\hline Step 1: Control variables & .14 & .15 & .18 & $.20^{*}$ \\
Branch dummy 1 & .17 & $.21^{*}$ & $.23^{* *}$ & $.23^{* *}$ \\
Branch dummy 2 & -.09 & -.13 & -.14 & -.19 \\
Age & .11 & .12 & .11 & .11 \\
Education level & -.03 & .04 & .06 & .11 \\
$\quad$ Tenure (in year) & & & & \\
Step 2: Independent variables & & $-.13^{*}$ & $-.16^{*}$ & $-.17^{*}$ \\
Surface acting & & $.25^{* * *}$ & $.21^{* *}$ & $.19^{* *}$ \\
$\quad$ Deep acting & & & & $.21^{*}$ \\
Step 3: Moderating variable & & & & $.19^{*}$ \\
$\quad$ Supervisory support & & & & $.16^{*}$ \\
Stpe 4: Interactive Effects & & & & $.19^{*}$ \\
Surface acting $\times$ Supervisory support & & $.09^{* * *}$ & $.04^{* * *}$ & $.06^{* * *}$ \\
Deep acting $\times$ Supervisory support & & & &
\end{tabular}

Note. $n=206$. Standardized betas were reported.

$* p<.05 ; * * p<.01 ; * * * p<.001$. 
Table 3. Study two: Means, standard deviations, correlations, and reliabilities of measures (in parentheses)

\begin{tabular}{|c|c|c|c|c|c|c|c|c|c|c|c|c|c|c|c|c|c|c|c|}
\hline & Variable & Mean & SD & 1 & 2 & 3 & 4 & 5 & 6 & 7 & 8 & 9 & 10 & 11 & 12 & 13 & 14 & 15 & 16 \\
\hline 1 & Hotel dummy 1 & .79 & .41 & --- & & & & & & & & & & & & & & & \\
\hline 2 & Hotel dummy 2 & .59 & .50 & $-.43^{* * *}$ & --- & & & & & & & & & & & & & & \\
\hline 3 & Supervisor's gender & .21 & .47 & -.17 & -.09 & --- & & & & & & & & & & & & & \\
\hline 4 & Supervisor's age & 31.19 & 7.38 & $.43^{* * *}$ & $.20^{*}$ & $-.24^{* *}$ & --- & & & & & & & & & & & & \\
\hline 5 & Subordinate's age & 24.33 & 6.12 & $.29^{* *}$ & .06 & -.18 & $.54^{* * *}$ & --- & & & & & & & & & & & \\
\hline 6 & Supervisor's education level & 2.50 & .63 & $.69^{* * * *}$ & $-.50^{* * *}$ & $.19^{*}$ & $.21^{*}$ & $.19^{*}$ & -- & & & & & & & & & & \\
\hline 7 & Subordinate's education level & 1.98 & .84 & .10 & -.17 & -.18 & -.05 & $.22^{*}$ & .07 & -- & & & & & & & & & \\
\hline 8 & Supervisor's tenure (in year) & 9.86 & 8.08 & $.51^{* * *}$ & $.20^{*}$ & -.07 & $.84^{* * *}$ & $.44^{* * * *}$ & $.28^{* *}$ & -.12 & --- & & & & & & & & \\
\hline 9 & Subordinate's tenure (in year) & 4.28 & 5.00 & $.37^{* * *}$ & -.11 & $-.26^{* *}$ & $.35^{* * *}$ & $.77^{* * * *}$ & $.19^{*}$ & $.21^{*}$ & $.27^{* *}$ & --- & & & & & & & \\
\hline & Dyadic tenure (in year) & 1.54 & 2.37 & $.20^{*}$ & .18 & $-.25^{* *}$ & $.40^{* * *}$ & $.33^{* * *}$ & -.04 & .01 & $.36^{* * *}$ & $.46^{* * *}$ & --- & & & & & & \\
\hline & Surface acting & 3.86 & 1.22 & -.04 & .09 & .09 & .05 & -.06 & -.13 & -.01 & .01 & -.06 & .01 & $(.86)$ & & & & & \\
\hline & Deep acting & 5.16 & 1.09 & .16 & -.04 & -.10 & .07 & .11 & .13 & -.05 & .05 & .15 & .10 & $-.20^{*}$ & $(.85)$ & & & & \\
\hline & Supervisory support & 4.00 & 1.69 & -.05 & -.02 & -.04 & $-.19^{*}$ & .05 & .12 & -.09 & $-.19^{*}$ & .16 & .15 & $-.22^{*}$ & $.28^{* *}$ & $(.91)$ & & & \\
\hline & Job satisfaction & 5.07 & 1.32 & -.02 & -.07 & -.14 & -.01 & .10 & .10 & -.06 & -.01 & .17 & .12 & $-.28^{* *}$ & $.26^{* *}$ & $.67^{* * *}$ & $(.82)$ & & \\
\hline & Burnout & 3.07 & 1.13 & -.04 & -.09 & .11 & -.03 & -.07 & .01 & .02 & .03 & -.04 & -.07 & $-.22^{*}$ & $-.25^{* *}$ & $-.24^{* *}$ & $-.32^{* * * *}$ & $(.95)$ & \\
\hline & Work performance & 5.04 & 1.61 & -.02 & -.11 & .09 & .01 & .15 & .01 & -.06 & -.02 & .11 & .03 & $-.22^{*}$ & $.22^{*}$ & .18 & $.36^{* *}$ & $-.28^{* *}$ & (.95) \\
\hline
\end{tabular}

Note. $N=111$ supervisor-subordinate dyads.

Gender: Female = 0; Male $=1$.

Education level: Junior secondary or lower $=1$; Senior Secondary $=2$; Vocational College $=3$; University or higher $=4$.

${ }^{*} p<.05 ;{ }^{* *} p<.01 ;{ }^{* * *} p<.001$. Two-tailed. 


\begin{tabular}{|c|c|c|c|c|c|c|c|c|c|c|c|c|}
\hline \multirow[t]{2}{*}{ Dependent variable } & \multicolumn{4}{|c|}{ Work performance } & \multicolumn{4}{|c|}{ Job satisfaction } & \multicolumn{4}{|c|}{ Burnout } \\
\hline & Model 1 & Model 2 & Model 3 & Model 4 & Model 5 & Model 6 & Model 7 & Model 8 & Model 9 & Model 10 & Model 11 & Model 12 \\
\hline \multicolumn{13}{|l|}{ Step 1: Control variable } \\
\hline Hotel dummy 1 & -.06 & -.05 & -.02 & -.10 & $-.52^{* *}$ & $-.51^{* *}$ & $-.33^{*}$ & $-.33^{*}$ & -.21 & -.23 & -.28 & -.28 \\
\hline Hotel dummy 2 & -.20 & -.21 & -.22 & -.24 & -.15 & -.16 & $-.21^{*}$ & -.14 & -.19 & -.19 & -.17 & $-.27^{*}$ \\
\hline Supervisor's gender & .13 & .18 & .13 & .10 & $-.32^{* *}$ & $-.27^{*}$ & -.16 & $-.21^{*}$ & .07 & .01 & -.02 & .04 \\
\hline Supervisor's age & .02 & .08 & .07 & .03 & -.24 & -.18 & .05 & -.01 & -.05 & -.12 & -.18 & -.11 \\
\hline Subordinate's age & .29 & .25 & .21 & .19 & -.01 & -.05 & -.08 & -.05 & -.16 & -.12 & -.11 & -.16 \\
\hline Supervisor's education level & -.09 & -.16 & -.02 & .02 & $.41^{* *}$ & $.33^{*}$ & .05 & .08 & -.02 & .06 & .14 & .10 \\
\hline Subordinate's education level & -.10 & -.08 & -.05 & -.05 & -.15 & -.12 & -.01 & -.01 & .06 & .03 & -.01 & .01 \\
\hline Supervisor's tenure (in year) & -.10 & -.11 & -.13 & -.06 & .28 & .27 & $.31^{*}$ & $.30^{*}$ & .30 & .31 & .30 & .31 \\
\hline Subordinate's tenure (in year) & -.06 & -.06 & -.24 & -.20 & .20 & .20 & .10 & .12 & .12 & .13 & .15 & .11 \\
\hline Dyadic tenure (in year) & .08 & .06 & .13 & .13 & .08 & .06 & -.08 & -.11 & -.07 & -.05 & -.01 & .04 \\
\hline \multicolumn{13}{|l|}{ Stpet 2: Independent variable } \\
\hline Surface acting & & $-.18^{*}$ & -.17 & -.17 & & $-.19^{*}$ & -.12 & $-.17^{*}$ & & $.20^{*}$ & .18 & $.25^{* *}$ \\
\hline Deep acting & & $.19^{*}$ & .14 & .13 & & $.21^{*}$ & .06 & .04 & & $-.19^{*}$ & -.15 & -.12 \\
\hline \multicolumn{13}{|l|}{ Step 3: Mediating variable } \\
\hline Job satisfaction & & & $.22^{*}$ & & & & & & & & & \\
\hline Burnout & & & & $-.25^{*}$ & & & & & & & & \\
\hline \multicolumn{13}{|l|}{ Moderating variable } \\
\hline Supervisory support & & & & & & & $.65^{* * *}$ & $.64^{* * * *}$ & & & -.19 & -.17 \\
\hline \multicolumn{13}{|l|}{ Step 4: Inteactive effects } \\
\hline Surface acting $\times$ Supervisory support & & & & & & & & $.25^{* *}$ & & & & $-.37^{* * *}$ \\
\hline Deep acting $\times$ Supervisory support & & & & & & & & $.20^{* *}$ & & & & $-.30^{* *}$ \\
\hline$\Delta R^{2}$ & & $.08^{* *}$ & $.02^{*}$ & $.02^{*}$ & & $.08^{* *}$ & $.29^{* * *}$ & $.05^{* *}$ & & $.08^{* *}$ & .01 & $.12^{* * * *}$ \\
\hline
\end{tabular}

Note. $\mathrm{N}=111$ supervisor-subordinate dyads.

Gender: Female $=0 ;$ Male $=1$

Education level: Junior secondary or lower $=1$; Senior Secondary $=2$; Vocational College $=3$; University or higher $=4$

$p<.05 ;{ }^{* * *} p<.01 ;{ }^{* * * *} p<.001$. Two-tailed. 


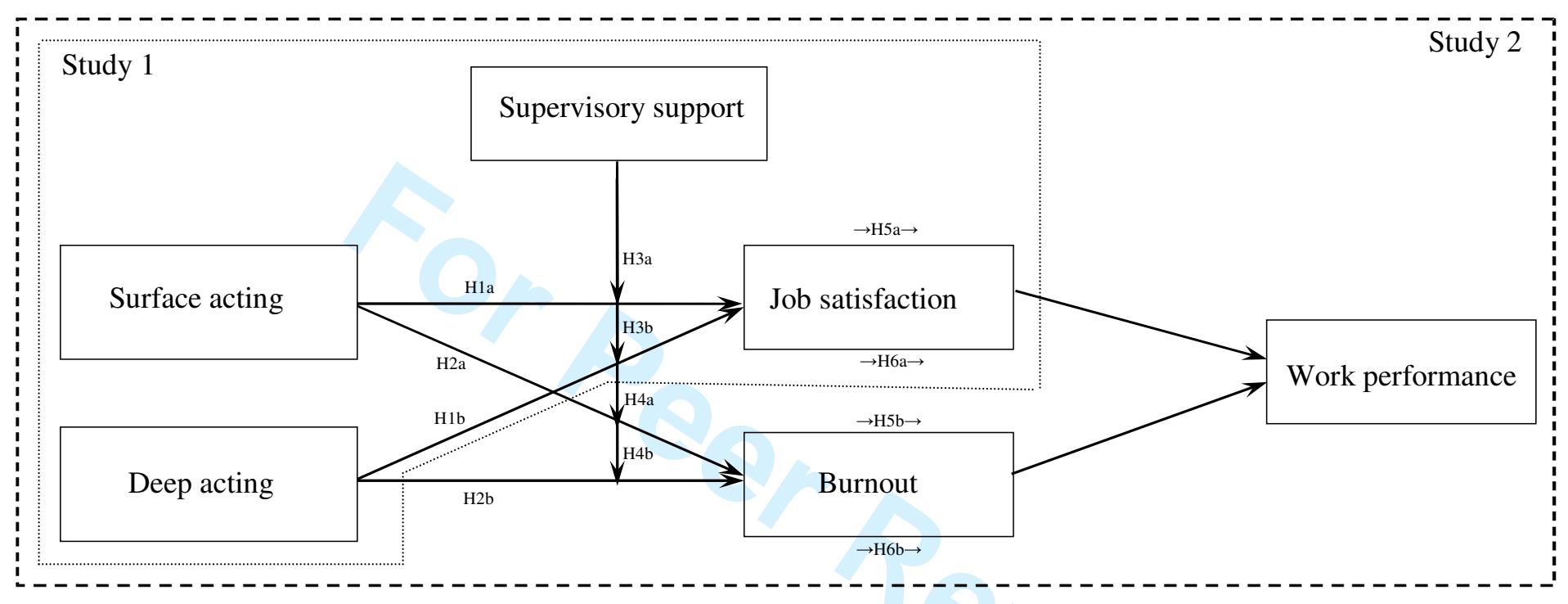

Figure 1. Research framework 
1

2

3

4

5

6

7

9

10

11

12

13

14

15

16

17

18

19

20

21

22

23

24

25

26

27

28

29

30

31

32

33

34

35

36

37

38

39

40

41

42

43

44

45

46

47

48

49

50

51

52

53

54

55

56

57

58

59

60
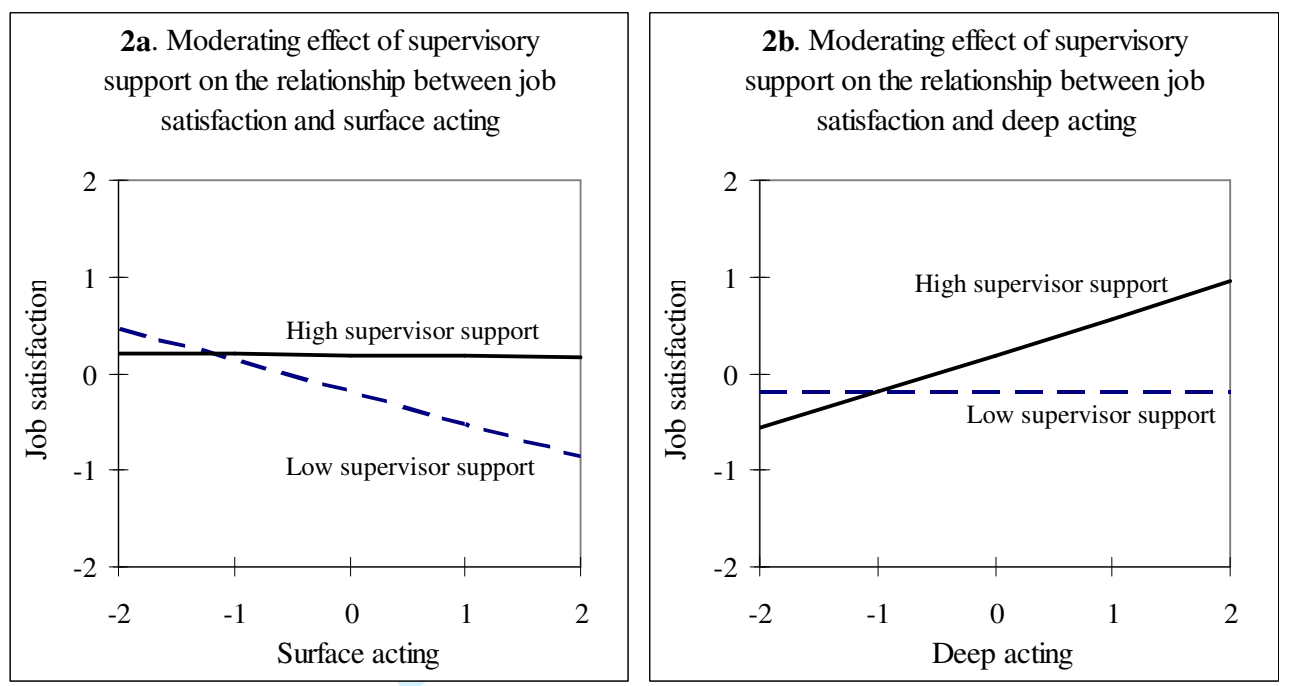

Figure 2. The moderating effects of supervisory support on the relationships between job satisfaction and surface acting (2a) / deep acting (2b) 
1

2

3

4

5

6

7

8

9

10

11

12

13

14

15

16

17

18

19

20

21

22

23

24

25

26

27

28

29

30

31

32

33

34

35

36

37

38

39

40

41

42

43

44

45

46

47

48

49

50

51

52

53

54

55

56

57

58

59

60
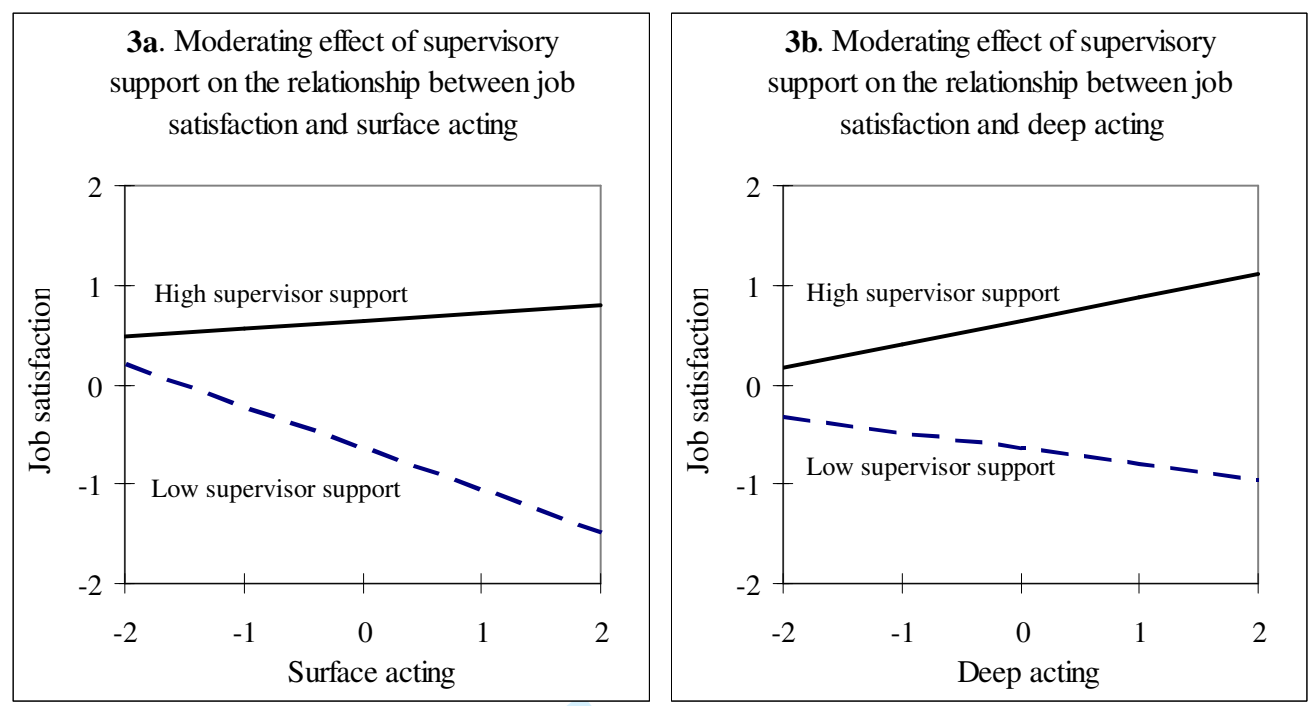

Figure 3. The moderating effects of supervisory support on the relationships between job satisfaction and surface acting (3a) / deep acting (3b) 
1

2

3

4

5

6

7

8

9

10

11

12

13

14

15

16

17

18

19

20

21

22

23

24

25

26

27

28

29

30

31

32

33

34

35

36

37

38

39

40

41

42

43

44

45

46

47

48

49

50

51

52

53

54

55

56

57

58

59

60
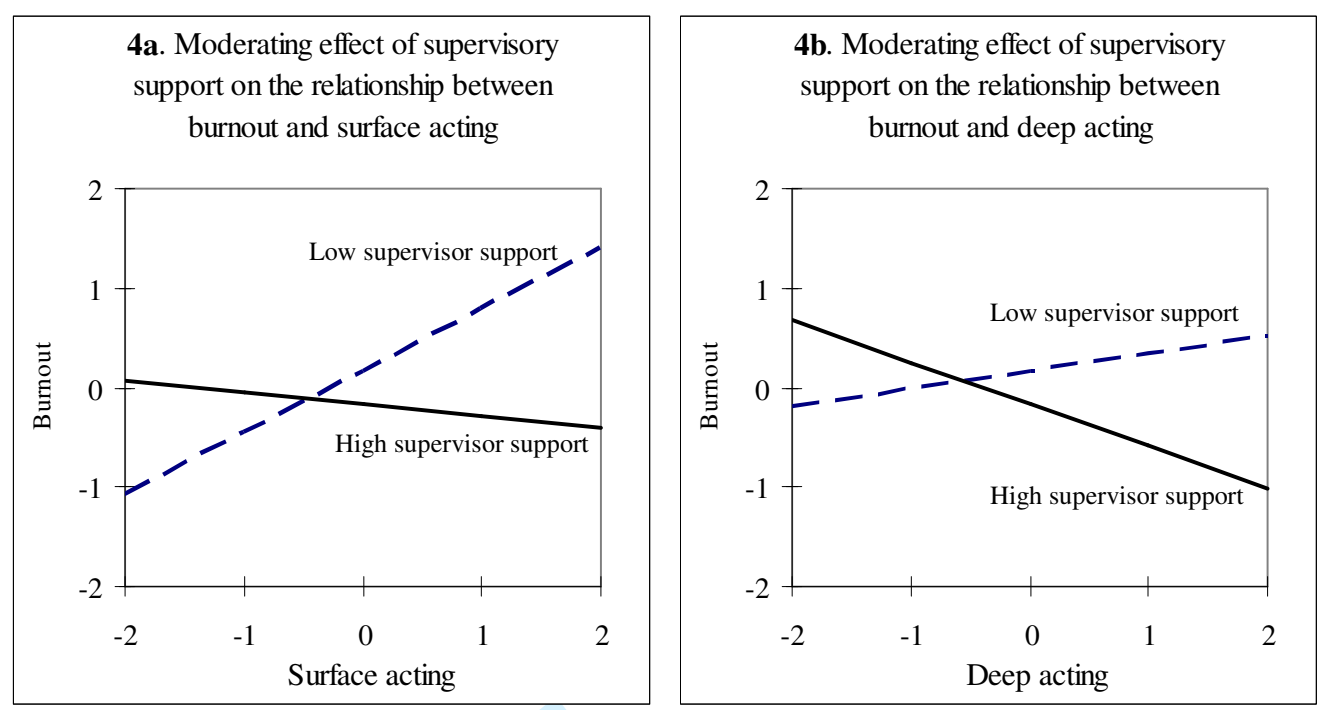

Figure 4. The moderating effects of supervisory support on the relationships between burnout and surface action (4a) / deep action (4b) 